Western University

Scholarship@Western

Education Publications

Education Faculty

2011

New Media and Online Mathematics Learning for Teachers

George Gadanidis

The University of Western Ontario

Immaculate Kizito Namukasa

The University of Western Ontario, inamukas@uwo.ca

Follow this and additional works at: https://ir.lib.uwo.ca/edupub

Part of the Education Commons

Citation of this paper:

Gadanidis, G., \& Namukasa, I. K. (2011). New media and online mathematics learning for teachers. D. Martinovic, V., Freiman, and Z. Karadag (Eds.), Visual Mathematics and Cyber learning (pp. 163-186). Dordrecht: Springer. 
New Media and Online Mathematics Learning for Teachers George Gadanidis and Immaculate Kizito Namukasa

\begin{abstract}
In this chapter we offer a case study of an online Mathematics for Teachers course through the lens of four affordances of new media: democratization, multimodality, collaboration and performance. Mathematics, perhaps more so than other school subjects, has traditionally been a subject that people do not talk about outside of classroom settings. However, we demonstrate through the case of the Mathematics for Teachers course that this does not have to be the case. Mathematics, even mathematics that traditionally has been seen as abstract or inaccessible, can be talked about in ways that can engage not only adults but also young children. The affordances of new media can help us rethink and disrupt our existing views of mathematics (for teachers and for students) and of how it might be taught and learned, by (1) blurring teacher/student distinctions and crossing hierarchical curriculum boundaries; (2) communicating mathematics in multimodal ways; (3) seeing mathematics as a collaborative enterprise; and (4) helping us learn how to relate good math stories to classmates and family when asked "What did you do in math today?"
\end{abstract}


Online courses for teachers have gained popularity in a short period of time. For example, in just over a decade our Faculty of Education has grown from two online courses to over 150 online courses offered in its Continuing Teacher Education Program, several fully online and hybrid courses in its Preservice Teacher Education Program, a fully online cohort in its Masters of Education Program and several online courses offered in the rest of its graduate program. At the same time, the nature of our courses is changing due to the increased availability of multimodal, interactive and collaborative forms of communication. While our first courses were designed to be primarily text-based, they are now making use of new media forms of communication, such as online videos, interactive content, and collaborative tools.

One of our online courses that makes extensive use of new media is the Mathematics for Teachers course, which we have been offering for the last 4 years as an optional summer course (in August) to each incoming elementary (K-8) teacher candidate cohort. Teacher candidates pay for this course in addition to their tuition and it is listed on their university transcripts as a separate course. The course is advertised for teacher candidates who fear and/or dislike 
mathematics and as a form of "mathematics therapy" (Gadanidis \&

Namukasa, 2005). The course offers teacher candidates opportunities to experience the pleasure of doing mathematics.

In this chapter we examine the design of the Mathematics for Teachers course through the lens of four affordances of new media: democratization, multimodality, collaboration and performance. In the context of analyzing students' course discussions and shared assignments, we ask: in what ways are these affordances present in our course design?

\section{Theoretical Perspective}

It is important to note that through our theoretical perspective, we see new media not simply as a tool for pursuing and amplifying our educational purposes, but also as an actor that shapes our thinking and our purposes. As Borba and Villarreal (2005) suggest, humanswith-media form a collective where new media serves to disrupt and reorganize human thinking. Likewise, Levy (1993) sees technology not simply as a tool used by humans, but rather as an integral component of a cognitive ecology of the humans-with-technology thinking collectives. Levy (1998) claims "as humans we never think alone or without tools. Institutions, languages, sign systems, technologies of communication, representation, and recording all 
form our cognitive activities in a profound manner" (p. 121). Levy

(1993) also suggests that technologies condition thinking, implying that the thinking collective of humans- with-media may persist even when the media is not present.

We are sympathetic to the view that the use of new media can help change how we think about mathematics education, and we have some anecdotal evidence from our personal experience.

However, in this exploratory work we do not try to prove a causal link between the affordances of new media and the design of the Mathematics for Teachers course. Comparing the affordances of new media to the design features of our course, and thus better understanding how new media affordances may be seen to be manifested or mirrored in our pedagogical choices, nonetheless, may be a first step in investigating how thinking-with-new-media affects how educators and researchers think about mathematics education.

\section{New Media Affordances}

For the purpose of this chapter, new media refers to technology tools that are widely and publicly accessible, such as the YouTube, Google, Facebook, Ning, wikis and blogs. Below we describe four affordances of new media that we use in our analysis of the Mathematics for Teachers course. 


\section{Democratization}

At the time of writing, the democratization affordance of new media is evident in the political upheavals in the Middle East, where hierarchical power relationships have been disrupted in part through the use of social media. In the last decade, authoritarian regimes that in the past have silenced political dissent are finding that new media tools have given people opportunities to express themselves through text, voice, and video (Al-Obaidi, 2003). In educational settings, new media also potentially disrupts existing power relationships in three important areas: (1) when/where learning takes place; (2) what curriculum and content is to be learned; and (3) who the teacher is. In a traditional classroom, what is available to learn is determined by "representatives" of hierarchical authority structures such as the teacher, the textbook and the mandated curriculum. Knowledge is classified by grade level and students do not have access to knowledge that is above their mandated grade. In contrast, a student in a new media setting can use Google or YouTube, for example, to search for information on a given topic they are studying or are curious about and freely access multimodal learning material that is not grade specific. Also in contrast to traditional education, where 
learning occurs in a classroom during a specified time period, new media learning resources are continuously available from any place with Internet access. Lastly, new media disrupts the labels of "teacher" and "student" as anyone with a camera and a YouTube account, for example, can teach about a topic of interest.

It needs to be cautioned, however, that the democratization affordances of new media do not provide a guarantee of democratization. Chester (2007) notes that there is a history of new communication technologies being subverted. In the classroom context, Cuban (1986), looking at 60 years of educational use of technology since 1920 notes that: classroom situations change minimally; when they do change, it is in non-standard ways; and, teachers and schools have a predominant effect on how technology is used in classrooms.

\section{Multimodality}

In contrast to the increasingly multimodal nature of the Web, many school experiences, especially in mathematics, continue to rely on discourses that are monomodal or bimodal (in cases where diagrams or graphs are employed). Kress and van Leeuwen (2001) suggest that in a digital environment "meaning is made in many different 
ways, always, in the many different modes and media which are copresent in a communicational ensemble" (p. 111). The shift from textbased communication to multimodal communication is not simply a quantitative change. It is not just a case of having more communication modes. It is a qualitative shift, analogous to the change that occurred when we moved from an oral to a print culture (Gadanidis, Hoogland, \& Hughes, 2008). Print culture, for instance, supported the creation of fixed media and records.

Kaput (2002) also talked about the new technologies, used in the world of business but yet to be harnessed in the world of education, as connected and inexpensive technologies as opposed to isolated and expensive technologies. He also talked about "newly intimate connections among physical, linguistic, cognitive and symbolic experiences [of mathematics concepts]" that become possible with newer computer and WWW technologies (p. 91) as used in learning mathematics. "Revisiting the analogies with change made possible by the printing press ..." (p. 92) he talks about the "impact of the printing press on the democratization of literacy." Kaput hypothesizes a similar change in the twenty-first century "relative to the new representational infrastructures made possible by the computation mediums" (p. 92). He also stipulates that the "crossing 
between interfaces [on hand-held, networked devises used for learning] may help in exposing the mathematics structure" (p. 97).

\section{Collaboration}

Our digital age has been labelled as an information revolution (as contrasted with the industrial revolution). Schrage (2001) suggests that this label misses the essence of the paradigm shift.

In reality, viewing these technologies through the lens of "information" is dangerously myopic. The value of the Internet and the ever-expanding World Wide Web does not live mostly in bits and bytes and bandwidth. To say that the Internet is about "information" is a bit like saying that “cooking" is about oven temperatures; it's technically accurate but fundamentally untrue. (p. 1, original emphasis)

Schrage suggests that a more appropriate label is relationship revolution.

The so-called "information revolution" itself is actually, and more accurately, a "relation-ship revolution." Anyone trying to get a handle on the dazzling technologies of today and the impact they'll have tomorrow, would be well advised to re-orient their worldview around relationships.... When it comes to the impact of new media, the importance of information is subordinate to the importance of community. The real value of a medium lies less in the information that it carries than in the communities it creates. (pp. 1-2; original emphasis)

Lankshear and Knobel (2006) suggest that the relatively recent "development and mass uptake of digital electronic technologies" represent changes on a "historical scale", which "have been 
accompanied by the emergence of different (new) ways of thinking about the world and responding to it." (pp. 29-30). These new ways of thinking can be characterized as “more 'participatory,' 'collaborative,' and 'distributed' and less 'published,' 'individuated,' and 'author-centric' ... also less 'expertdominated."' (Knobel \& Lankshear, 2007, p.9).

\section{Performance}

Hughes (2008) and Kress and van Leeuwen (2001), note that the multimodal nature of new media offers performative affordances. This is evident in the multimedia authoring tools used to create online content, such as Flash, which often use performance metaphors in their programming environment. For example, you program on what is referred to as the "stage", you use "scenes" to organize "actors" or "objects" and their relationships, and you control the performance using "scripts". The Web as a performative medium is evident in the popularity of portals like YouTube. Hughes suggests that the new media that is infusing the Web draws us into performative relationships with and representations of our "content". Gadanidis and Borba (2008) have explored digital performance in mathematics education settings, and the idea of students as performance mathematicians. 


\section{Research Setting and Participants}

We study the design and implementation of a Mathematics for Teachers online course. This online course makes extensive use of new media. We have been offering it for the last 4 years as an optional summer course (in August) to each incoming elementary (K-8) teacher candidate cohort. Teacher candidates choose to enroll and pay for this course in addition to their tuition. Because the course is advertised for teacher candidates who fear and/or dislike mathematics several teacher candidates who enroll for it have specific needs for learning mathematics in different ways than those that likely turned them away from mathematics. The course, therefore, offers teacher candidates opportunities to experience the pleasure of doing mathematics.

In the summer of 2010, 37 elementary school teacher candidates attended the course. They consented to having their course participations used for research purposes. One of the online resources used in the course is the www.researchideas.ca website, where in collaboration with project schools we are creating multimodal and performative documentaries of how the "content" of our Mathematics-for-Teachers courses has been used in elementary school classrooms. In this paper we draw data from the Summer 
course online conversations.

\section{Methods: Analyzing the Mathematics for Teachers Course}

In the next section we analyze the design and implementation of the summer of 2010 Mathematics for Teachers course. We use a case study approach, with the course design, mathematics activities, and teacher candidate contributions to the online discussion constituting a single case. Case study method is suitable for collecting and retelling in-depth stories of teaching and learning and for studying a 'bounded system' (that is, the thoughts and actions of participants of a particular education setting) so as to understand it as it functions under natural conditions (Stake, 2000a, 2000b; Yin, 2006). The analysis is qualitative in nature, in keeping with the established practice of in-depth studies of classroom-based learning and case studies in general (Stake, 2000a). Content analysis is employed to identify, code and organize patterns of discourse (Denzin \& Lincoln, 2005; Patton, 2002) that fit the four new media affordances noted above: democratization, multimodality, collaboration and performance. The case study answers the question: in what ways are these affordances present in our course design? The style of writing of the case study is at once analytical (using the four new media affordances) and descriptive (offering a detailed account of the 
Mathematics for Teachers course experience).

\section{Democratization}

In what ways did the Mathematics for Teachers course reflect the democratization affordances of new media?

\section{Where/When Learning Takes Place}

Using an asynchronous online discussion platform, teacher candidates had access at any time and from any place with an Internet connection. Had we offered the course in a university classroom we would have limited the number of participants due to (a) increased cost of accommodation for out-of-area participants, (b) summer employment commitments, and/or (c) summer vacation plans. In fact, some of the teacher candidates participated in the course while working or vacationing outside of Ontario, and across various time zones.

\section{What Is to Be Learned}

The mathematics in our Mathematics for Teachers course disrupts common conceptions of content in two important ways. First, we don't distinguish between the mathematics that teachers study and 
the mathematics that students study (Gadanidis \& Namukasa, 2007).

That is, the activities we bring to our Mathematics for Teachers course are the same activities we use with students in elementary school classrooms. Second, the activities are designed to have a low mathematical floor, allowing for engagement with minimal prerequisite knowledge, and a high mathematical ceiling, allowing for extensions to more complex ideas (Gadanidis \& Hughes, 2011). We elaborate on these ideas below.

\section{Mathematics for All}

Balland Bass (2003), Ball (2002), and Davis and Simmt (2006) distinguish mathematics-for-teaching from the mathematics that students need to know. Ball, Bass, Sleep, and Thames (2005) give the example of the mathematical task of $307-168=139$ and state that " $[\mathrm{t}] \mathrm{o}$ teach, being able to perform this calculation is necessary. But being able to carry out the procedure is not sufficient for teaching it." They identify four distinct domains of mathematical knowledge for teaching:

(a)common content knowledge (calculating the answer to 307 168),

(b) specialized content knowledge (such as analyzing calculation errors), (c) knowledge of students and content (identifying student 
thinking that might have produced such errors), and (d) knowledge of teaching and content (recognizing which manipulative materials would best highlight place-value features of the algorithm). The suggestion is that the last three domains - knowledge of specialized content, of students and content, and of teaching and content distinguish what teachers need to know from what students need to know. This work on mathematics-for-teaching offers a powerful unit of analysis of teacher education and development. However, the distinction that mathematics-for-teaching is different from students' mathematics may not fit well with research-based reform recommendations, where students are also expected to be engaged in the four mathematics-for-teaching domains identified by Ball et al.: performing calculations, analyzing errors, identifying thinking that might have produced such errors, and selecting tools for modelling mathematical ideas (e.g., Ontario Ministry of Education, 2005).

Begle (1979), Eisenberg (1977), Fennema and Franke (1992), General Accounting Office (1984), and Monk (1994) note that university mathematics courses may not offer the mathematics knowledge that teachers need for teaching. An emphasis on more mathematics may be inappropriate (Davis \& Simmt, 2006). We agree that offering teachers more of the mathematics that turned 
them away from the subject is not helpful. But, that teachers need a totally different mathematics than what they experienced during their schooling does not necessarily imply that they need a different mathematics than their students. Rather, we think it implies that both teachers and students need to experience a better mathematics that is aligned to reform initiatives such as teaching through problem solving and focusing on understanding mathematical concepts (NCTM, 2000).

\section{Low Floor, High Ceiling}

How do we stretch mathematical concepts so that the key ideas are accessible across grades? This is not an easy task as traditionally our pedagogical thinking has focused in the opposite direction, by making mathematics content grade specific. Below we provide two examples of activities from the Mathematics for Teachers course that are designed to have a low mathematical floor, allowing engagement with minimal prerequisite knowledge, and a high mathematical ceiling, offering opportunities for extending ideas to more complex and more sophisticated representations. 


\section{Infinity and Limit}

The Mathematics for Teachers course started with a module consisting of an activity on the themes of infinity and limit, which are typically covered in grade 11 through the topic of sequences and series and in grade 12 through Calculus. One goal of the activity is to help teacher candidates who fear mathematics realize that topics that are usually considered abstract and complex can be accessed in meaningful ways even by young children. In fact, a similar activity was completed by grades $2-3$ students at a summer camp (as a context for exploring representations of fractions) and a grade 4 classroom (as an exploration of linear measurement). Videos of the students and one of the teachers were available online for teacher candidates to view. All mathematics tasks were available at once, and teacher candidates were encouraged to complete the tasks in the sequence listed in order to achieve the best experience possible. After completing each task, they were asked to share and discuss their findings online. The tasks are carefully designed and sequenced to help teacher candidates experience mathematics ideas in new ways and in new light, and elicit mathematical surprise.

The first task of the module, specifically, asked teacher candidates to consider the following questions: (1) What do you 
know about infinity? (2) How big is it? (3) Can it fit in a gym? (3)

Can you hold it in your hands? There was consensus among teacher candidates that infinity would not fit in a gym or in their hands.

Three representative comments are listed below.

By definition, infinity cannot be assigned a number value, and in math I believe it is usually associated with a symbol.

It is all around us as "time" and "space".

Infinity is not something tangible, as it is a concept that is greater than any measurable space, like a gym. It cannot be held in your hand.

In the second task, teacher candidates accessed, printed and completed a handout consisting of ten 16x 16 grids, with the first one shaded to represent the fraction $1 / 2$. For each of the subsequent grids they were asked to shade in representations of the fractions $1 / 4,1 / 8$, $1 / 16,1 / 32,1 / 64,1 / 128,1 / 256,1 / 512$ and $1 / 1024$, respectively. The last page had a 32x32 grid with the following instructions: "Suppose you repeated the above process forever. Now imagine taking all of the shaded pieces and joining them together to form one solid shape. What might the shape be and what would its size be? Draw the shape on the grid below." (see Fig. 1)

Teacher candidates were then asked to consider the following "walk to the door" task. 
- You are standing in a room, facing an open door, which is $1 \mathrm{~m}$ away from you.

- Is it possible to walk to the door, and actually go past it, and leave the room?

- You're probably thinking this is a silly question, and that of course you can walk to the door, and even walk past it. After all, it's open.

- But think of it this way: To get to the door, you first have to first pass half of the distance to the door ( $1 / 2$ of a metre), then half the remaining distance to the door.

Fig. 1 The finite sum of an infinite number of fractions

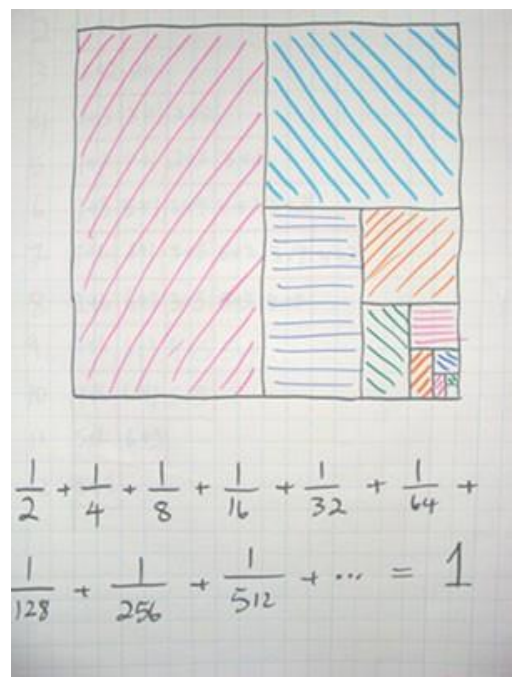

(1/4 of a metre), then half of the remaining distance ( $1 / 8$ of a metre), and so on and on and on ... 
- So let me ask again, can you reach the door if you have to actually travel $1 / 2$ of the distance, then $1 / 4$, then $1 / 8$, then $1 / 16$ and so on?

- What does this tell us about the sum of $1 / 2,1 / 4,1 / 8,1 / 16$, and so on forever?

- Here's a song by grade 4 students on this theme ... http://www.edu.uwo.ca/mpc/ mpf2010/mpf2010-131.html

- Teachers candidates also read a retelling of the story of Rapunzel, where Rapunzel's tower cell door is open but she does not escape because she is imagining passing through all the fractional distances discussed above.

Teacher candidates were also asked to consider the sum of the following infinite set of fractions: $1 / 2+1 / 4+1 / 8+1 / 16+1 / 32$ $1 / 64+1 / 128 \ldots$ and to decide if there is a sum and what it might be. Then teacher candidates viewed the following online videos:

- A teacher talking about this activity (done with grade 23 students) http://www.edu.uwo.ca/mpc/camp2010/day4/infinity2. html

- Songs by the grade $2-3$ students on the theme of infinity http://www.edu.uwo.ca/mpc/camp2010/day4/infinity1.html http://www.edu.uwo.ca/mpc/camp2010/day5/ms9.html 
http://www.edu.uwo.ca/mpc/camp2010/day5/ms10.html

Historically, mathematicians have struggled with the concepts of infinity and limit, as is evident by Zeno's paradoxes, which "have puzzled, challenged, influenced, inspired, infuriated, and amused philosophers, mathematicians, and physicists for over two millennia" (Tall \& Tirosh, 2001; Wikipedia, 2011). The "walk to the door" problem posed in the Mathematics for Teachers course is a variation of Zeno's paradoxes. The traditional curriculum keeps the ideas of infinity, be it the limiting processes or finite values of limits, away from children, typically until they reach grades 11 and 12 .

Fig. 2 Arrays for the number 4
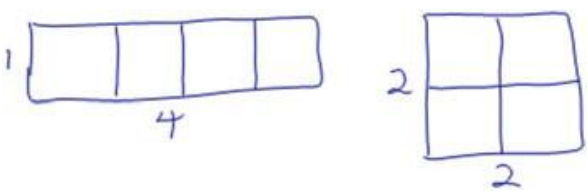

Through the above activities, using familiar contexts of fractions and halving, teacher candidates came to realize that these ideas are in fact accessible to young children who are curious about ideas such as infinity even at kindergarten.

I thought that this concept would be difficult to teach to anyone, let alone young students. After watching the videos, it became apparent that the students were in fact able to understand the idea of infinity and represent it in visual form. 
I was struck by the seeming simplicity of infinity (and its explanations) in all of this. Kids appeared to have little trouble grasping the fact that "infinity never stops" (to quote one of their catchy tunes).

The exercise that the children did by creating the piece of paper to represent infinity was great. What I got out of the exercise and videos is that an abstract concept can go along way and be brought into easier terms for the students, causing them to express enthusiasm and creativity through a tangible means and at the same time using other media such as music and drama.

Previous encounters with infinity usually involved an explanation that managed to complicate the whole thing unnecessarily. I am far less intimidated by infinity now.

\section{Optimization}

Another mathematics activity of the Mathematics for Teachers course involved an exploration of optimizing perimeter for a given rectangular area. Teacher candidates accessed, printed and completed a handout where they drew rectangular representations of the numbers 1 through 12. For example, two possible arrangements for the number 4 are shown in Fig. 2. Then they were given the following problem.

Imagine that you are planning for a mathematics party.

- You have 16 square tables that you can use to form a bigger rectangular table (like the rectangular arrays you created for the numbers $1-12$, with no holes in the middle) 
- What arrangement would you use so you can fit the most number of chairs around the big table?

- What arrangement would you use so you can fit the least number of chairs around the big table?
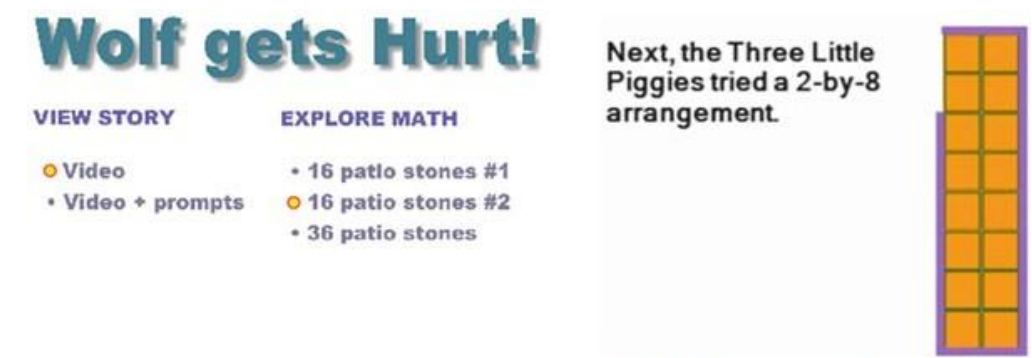

16 PATIO STONES \#2

How many different ways can we arrange 16 linking cubes in a rectangular array?

Move the mouse over the table to see the different arrangements possible.

Which arrangement has the smallest perimeter?

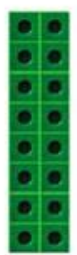

\begin{tabular}{cc} 
ARRANGEMENT & PERIMETER \\
1 by 16 & 34 \\
\hline 2 by 8 & 20 \\
\hline 4 by 4 & 16 \\
8 by 2 & 20 \\
16 by 1 & 34 \\
\hline
\end{tabular}

Fig. 3 The story "Wolf gets Hurt"

Use the grid in the handout to show the various table arrangements and the number of chairs that fit.

Then teacher candidates accessed an online story called "Wolf gets hurt" (see Fig. 3) that included a video reading and interactive mathematics content. In this retelling of the Three Little Pigs story, the Piggies capture Wolf and try to build the biggest rectangular pen possible with only $18 \mathrm{~m}$ of fence. They also accessed (1) an online 
video of a grade 2 teacher describing how she did this activity with her students (2) a video of the song that summarized the learning of the grade 2 students and (3) a stop motion animation video created by a teacher candidate who took the Mathematics for Teachers course in 2008:

- Teacher interview: http://www.edu.uwo.ca/mpc/bigideas/arrays

- Student song: http://www.edu.uwo.ca/mpc/bigideas/arrays/perimeter.html

- Animation: http://www.edu.uwo.ca/mpc/mpf2010/mpf2010106.html

Optimization is a topic that is typically not taught until grades 9 and 10, when students first encounter quadratic functions. It is also part of the grade 12 Calculus curriculum. It can also potentially be found in grades 5 and 6, where students explore relationships between area and perimeter. However, when we have included optimization activities in workshops for grades $4-6$ teachers, most teachers express surprise that the perimeter can change if the area does not, indicating that they have not addressed these area/perimeter relationships in their classrooms. Similarly, teacher candidates in the Mathematics for Teachers course were surprised by the optimization relationships between area and perimeter. 
I thought originally that I understood arrays, and immediately saw how it could be a lesson that might lead to factoring and such. Having to do the activity myself though, slowing down and taking the time, I found myself incredibly humbled.

Terrific way to see how you can make the perimeter change.

I learned that perimeter changes as shape changes, even though the area stays the same, and that there are fun ways to express this.

I felt amazed at the patterns and relationships present in math - it really is cool that when area stays the same but changes shape, the perimeter changes.

They also realized that these concepts are accessible to young children, like the grade 2 students in one of the teacher interviews that they could view online, along with student samples of work. My most significant insight from Module 2 was the number of activities that were involved to teach one concept to children. When learning about arrays, the teacher had the children perform various activities. They read stories, learned about division with distributing their "cookies", created arrays and drew real life objects, used linking cubes and grid paper, and made up and performed songs. It seems like a lot of activities to learn one concept. However, as I watched the explanation of each activity and what the children learned, even I began to feel as if the concept was more ingrained in my memory. I also liked how the activities could be related to real life to make them more concrete and easily understood.

I enjoyed looking at multiplication arrays and doing the Math Party. I had my 5 year old work alongside me and he understood as well, and thought it was pretty neat to have a different number of chairs around the table with the different arrangements. 
The preceding quote from one of the teacher candidates noted that the tables and chairs representation made the concepts of area and perimeter optimization accessible to her 5 year old child.

\section{Who Is the Teacher}

The role of the instructor in the Mathematics for Teachers course was to pose problems and scaffold and encourage teacher candidates to individually and collaboratively explore multiple solutions and representations. The instructor avoided giving answers or commenting on whether answers were correct. This helped create an atmosphere (discussed in greater depth in the section on collaboration) where teacher candidates relied on one another for learning.

Sharing ideas with 30-some people in the manner we have also has confirmed for me that every class member will have their own take on the material and their own gift to offer to the discussion.

I think it is SO important to work as a group and allow students to teach each other concepts as well, because who [is] better to teach something than someone who has JUST learned it! (Capitalization emphasis in original)

The use of video resources of classroom teachers discussing the activities of the course from the point of view of how they were 
implemented in their classrooms as well as videos of young students sharing their mathematics learning helped expand the scope of who the teacher was.

The interview with Pam King and the song were helpful to watch. The song especially for me reinforced that $2 \times 6$ and $6 \times 2$ though mathematically the same, are two different ideas to children. 2 friends sharing 12 cookies, or 6 friends sharing 12 cookies - sooooo not the same thing to youngsters :)

The children in all of the examples had a much better and more simpler means of understanding infinity and I LOVE that!

External resources including interviews with classroom teachers and performances by school children on the problem had a significant impact on the mathematical and pedagogical learning of teacher candidates. This helped to reinforce the idea that fellow teachers and even our students can be our "teachers".

\section{Multimodality}

Teacher candidates noticed the multimodal nature of the course experiences and made ongoing comments about them. Figure 4 shows a screen shot of the interview with a Grade 2 teacher on the theme of optimization. Figure 5 shows the optimization stop-motion animation created by a teacher candidate in the 2008 Mathematics for Teachers course.

Following are representative comments about multimodality that 
arose from the infinity activity.
All of this caused me to reflect on how I was taught in the lower grades as I recall far less visual aids and interesting stories. It impressed on me how much more effective teaching a subject could be if you present it in different formats (stories, videos, puzzles) rather explaining it and giving work to try out. This really has made me think about how teaching has evolved too.

I found the structure of this exercise appealing because it (1) began with an intellectual challenge (i.e., the request that we interrogate our understanding of what "infinity" refers to); (2) invited us to engage in a series of hands-on paper-and-pen tasks; and, after encouraging us to contemplate the import of our doing so; (3) exposed us to a novel way in which an elementary school teacher has attempted to introduce the concept of infinity to her students and, simultaneously, elicit their creativity. Contemplating my reaction to these activities, I realized that what made the activity especially enjoyable was that it was not singular in its style of delivery and, instead, included activities that would appeal to different "types" of learners.

Teacher candidates made similar comments about the optimization activity.

(I have developed an) awareness that one doesn't have to explain a mathematical concept using only the lexicon of that discipline and with a singular reliance upon other mathematical concepts - one can/should exercise one's creativity and, in doing so, encourage students to think holistically - to merge a mathematical concept with the concerns of other subjects - health studies, social studies, etc.. 

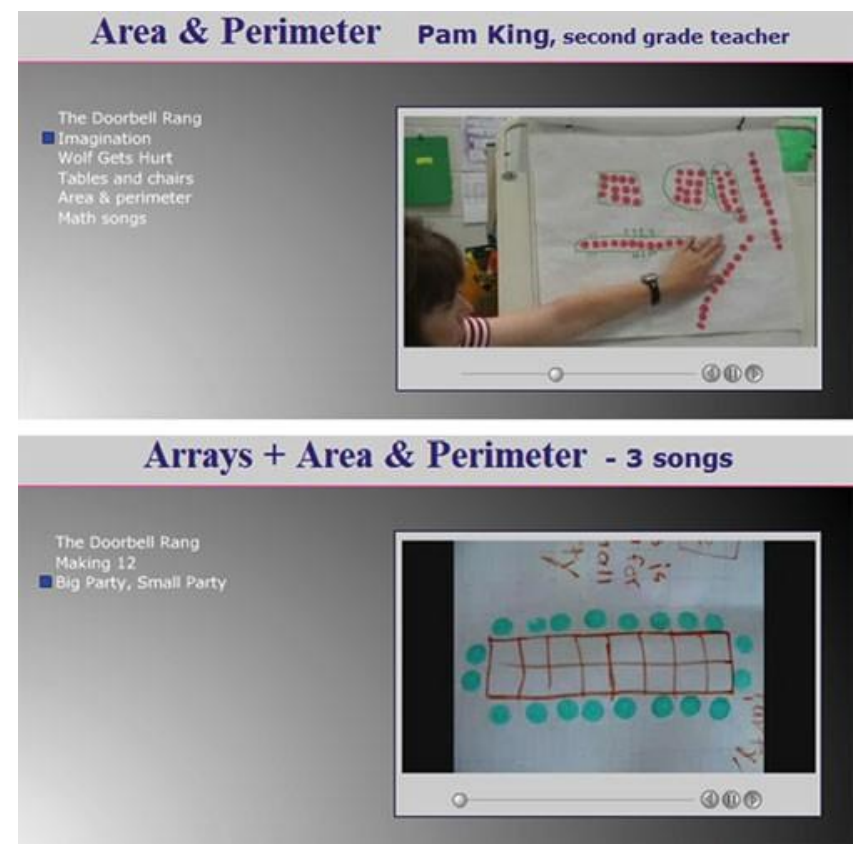

Fig. 4 Screenshots of teacher interview on optimization in Grade 2

Fig. 5 Screenshot of optimization stop-motion animation

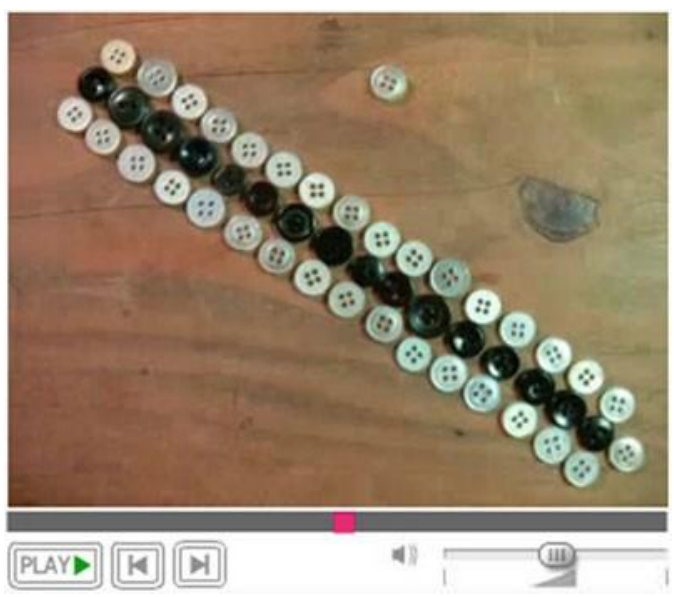


After doing the assignment and watching the videos, I noticed that the visual representations made the concepts of area and perimeter more clear to me.

Treating math as a fun interplay between numbers (i.e., watching the buttons move around) and asking questions that require a little imagination from the learner seem to be very effective in making math a subject to enjoy.

When I did the activities for this module and saw the video of the animation that visually demonstrated area and perimeter, I was surprised by how much these visual representations helped to clarify the concepts even for me. It opened my mind to the possibility of using visual aids to help explain math, and has therefore changed my mind about taking a strictly auditory approach to the subject.

I really enjoyed seeing the different ways that this lesson can be taught. I thought the button video was a really cool idea, having the different colour buttons and seeing that each time there are always 16 black buttons, (as the area doesn't change) but that different amounts of white buttons were needed as the perimeter does change.

I have been wondering whether Pam King's methods may be too time consuming for a rigid classroom schedule. With more thought, I feel that developing a solid foundation in basic mathematical concepts is worth the time and effort Pam places in the planning and execution of her lesson. Really, she is able to kill two birds with one stone, as she incorporates music and English into her math lessons.

For me I find visual examples to be very helpful, but I agree that all students learn differently, so it was neat to hear the songs and story which explained the lesson in a different way.

Teacher candidates also used multimodal ways to present their own ideas in the discussion, such as creating drawings and diagrams 
expressed their learning. One of them had this to say:

I definitely enjoyed this course. It has been an eye opener because it was not at all what I was expecting. I love writing poetry, photography, music and art and now to have learned that I can use all of the above to teach math gave me insight to how I view math and how I have been afraid all these years.

For example, one of the teacher candidates wrote a song called

“The infinity cake", shown in Fig. 6 and available as a musical performance at http://www.joyofx. com/music/m4t-2010infinityCake.html.

\section{Collaboration}

Several teacher candidates commented that they had low expectations of the level of community that could be experienced in an online course.

Admittedly, I was not expecting genuine community from an online course

I had worried that taking a course that didn't involve in-class lectures would be intimidating and impersonal.

The course design attempted to create a sense of community and a collaborative spirit in the following ways. To reduce stress, especially since many elementary school teacher candidates fear or dislike mathematics, the course did not have any mathematics 
content tests and no final examination. In addition, to take the focus away from mathematics achievement, the course used a pass/fail assessment scheme. The standard for achieving a passing grade was high, based on a B or $75 \%$ level of performance on course assignments. However, none of the assignments required a mastery of any given set of mathematics content. Rather, the assessment expectation was that teacher candidates (a) explore a variety of ways of seeing or connecting mathematics concepts, (b) reflect deeply on mathematics teaching and learning, and (c) participate in course discussion on a regular basis. The comments made by the instructor focused on providing positive feedback and conceptual scaffolding when necessary. The course discussion was organized in smaller groups of 9-10 people in a discussion area, however teacher candidates had the freedom to read the discussions of other groups, and also comment on them. 
Fig. 6 Lyrics of song

"The infinity cake"

\section{The Infinity Cake}

I have the most delicious cake

I want the world to sample

I didn't have much time to bake

But I think just one

should be ample

All my friends had a laugh

They said it could not be done

But I'll just keep cutting

my cake in half

Until the whole world

has had some

I cut my cake in half for you

And gave a quarter to him

One eighth went to little Sue

And one sixteenth to Jim

The cake kept shrinking

My friends kept laughing

But I knew just what to do

I simply took what I had left

and cut it into two

At the end of the day

they all had a treat

Ever so small it may be

I smiled at my friends saying

"This was no feat"

Because I knew fractions

were the key

It was evident that teacher candidates read the discussions of other

groups, as they regularly made explicit references to ideas discussed

outside of their own discussion area. Part of the course discussion

occurred in a wiki environment, where teacher candidates worked in

small groups to collectively identify what they learned from certain

activities and how they felt about the experience. The opportunity to

express feelings, gave teacher candidates the opportunity to realize

that they came to the course with a shared view of mathematics

(fearing or disliking the subject) and shared similar experiences of 
initial apprehension and subsequent surprise and delight about the mathematics patterns they explored.

It is also important that the course focused on mathematics with (1) a low floor, allowing teacher candidates to engage with minimal mathematics knowledge, and (2) a high ceiling, offering opportunities for deep mathematical insight and consequently mathematics that is worth talking about. In traditional mathematics education, as will also be discussed in the next section on performance, when a student is asked "What did you do in math today?" the typical response is "Nothing" or "I don't know". Teacher candidates found the mathematics in this course interesting to talk about and in course discussions even related stories of their related mathematics conversations with family, friends and coworkers.

Below are representative comments about the community and collaborative nature of the Mathematics for Teachers course.

This class, in the course of a single week, has fostered a greater sense of "community" and involvement among students than any of the classes that I took (including seminars with a very small group) during the course of my 4 year-undergraduate degree. It's really wonderful to read all the warm and supportive feedback that each submission has garnered (and I'm sure that others are equally appreciative, especially since so many of us admitted in our introductory remarks that we were white-knuckled re: teaching math). I have never taken an on-line course until now and it is 
awesome. I too feel the "community" atmosphere with everyone by such positive feedback, words of encouragement and creative energy from all.

I'm enjoying learning because of the safe environment everyone here has helped to create. I so appreciate that.

I have always been an individual who is nervous about participating in class and writing comments on discussion boards. This course has managed to help me break down my barriers and feel more confident in my ideas, comments, math ability, and myself overall.

Hope that, in the future, I can encourage this kind of welcoming atmosphere in the classes that I teach.

In a hybrid course or in a fully online course involving students who met face to face before a sense community would be more expected in. In the four reflections above, it is surprising, that students in a fully online mathematics class experienced, in their own words, a sense of warm, supportive, positive, energizing, and safe community.

\section{Performance}

What makes for a good performance? Boorstin (1990) identifies three pleasures that we derive from performances such as movies: (1) the new and the surprising; (2) emotional moments; and (3) visceral sensations. It is interesting that Norman (2004) states that his principles for technological design "bear perfect correspondence" to the principles of what make movies work identified by Boorstin. 
These principles have been used in Canada and in Brazil to research how they might be used as a basis for pedagogical design in mathematics education and how they might help us see teachers and students as performance mathematicians (Gadanidis \& Borba, 2008; Gadanidis \& Hughes, 2011). Below we use Boorstin's principles of what makes movies work to examine the performative nature of experiences in the Mathematics for Teachers course.

\section{New and Surprising}

Good movies take you to a new world. The wide angle camera shot is a typical tool used in movies to give the audience of the new world in which the plot will unfold. Good movies also surprise you. When you watch a movie, you typically guess ahead; if your guesses are always correct, the movie becomes predictable and less interesting; however, if your guesses are incorrect then you experience the pleasure of surprise.

As two teacher candidates commented,

After doing the activities and watching the videos I learned that it is possible to explain the concept of infinity to everybody. I guess I was initially thinking that it would be an impossible concept to explain clearly since it doesn't have a beginning or an end but now I see how it is possible. 
a way I haven't before.

It surprised me at how comfortable I felt and that it was a simple way to explain it to children.

The course intentionally sought to offer teacher candidates opportunities to see mathematics in new and wonderful ways. The design of low floor, high ceiling mathematics activities can be seen as being equivalent to the wide angle camera shot in movies. It helped teacher candidates see traditionally abstract concepts such as infinity and optimization as accessible.

After watching the videos, I learned that *shock* [sic] you can hold infinity in your hands! It is surprising to see that there are ways of representing something so abstract and conveying these themes to such young students. (Asterisks in original)

I felt amazed at the patterns and relationships present in math - it really is cool that when area stays the same but changes shape, the perimeter changes.

Wow this activity completely changed how I looked at the concept of infinity.

Teacher candidates also experienced mathematical surprise, both from a mathematics and a pedagogical perspective.

\section{Emotional Moments}

Good movies help you experience emotional moments (vicariously through the actors). One of the opportunities that teacher candidates had to experience emotional moments in the course was by sharing 
how they felt during their mathematics activities of the course. One area of "feeling" that they commonly expressed was their unease with mathematics. This is not surprising as the course was advertised for teacher candidates who fear and/or dislike mathematics.

Representative comments by the teacher candidates listed below indicate that in fact the majority fell in this category.

I know when I received the email describing this course, I just kept saying "that's me ... that's me!" I immediately knew I had to take this course.

I feel that others are in the same boat as I am when I read other comments about the "fear" of math.

I think it seems to be a common thread that many of us found math "scary" or intimidating.

I struggled so much with math throughout my schooling years but [the reason] wasn't because I wasn't good at it, I just needed more than one way of learning it. It led to many frustrating nights.

I grew up hating math.

Some teacher candidates also expressed an apprehension about taking the course.

What really surprised me in this course, is that there are a lot of people who felt the same way I did, very hesitant about starting this course at first, but felt it was important in order to be a future educator.

When I signed up for this course I was uptight and scared because I thought 
that we were going to be going back to the old way of learning a lesson.

As a student, I always was aware that math was a very important subject, but I was never taught it in a way where I actually enjoyed it.

The methods that it was taught to me also did not help ... I was often told to "just do it".

As the course progressed, however, teacher candidates made repeated comments about the positive effect of course activities on their view of mathematics.

At the beginning of each lesson so far I have felt a little anxious because I am realizing how much math I do need to brush up on. However, after completing each lesson I am feeling much more confident in my math abilities!

When I signed up for this course I was very hesitant on taking it, but even more hesitant in taking a math course in the fall. You have dispelled my anxiety.

This will make a huge difference in how I teach math!

Math was never taught to me ever in such a creative, fun, interactive, and interpretive way!

Children's literature was used to either introduce or supplement all of the mathematics activities of the Mathematics for Teachers course. This created an opportunity for teacher candidates to experience mathematics through the characters involved and vicariously experience their emotional moments. Teacher candidates made overwhelmingly positive comments with respect to the use of 


\section{children's literature.}

I really enjoyed the 3 little pigs video as a learner. I wanted to watch to the end.

I felt at ease with this lesson. Incorporating the story of the three little pigs and wolf into learning arrays helped to keep me focused because I was also interested in the other (environmental) lesson I was learning with the wolf's story.

I found the best activity for me was the wolf story. I suppose this is because I am such a reader and really connected to the visualizations.

The use of stories and math is wonderful! A math lesson is taught but also as in Wolf Gets Hurt, an underlying message is relayed! Clever!

I loved the moral of the story and I think the best thing a teacher can do is just create interest so the child wants to find out more for themselves.

Wolf gets hurt: Having a dialogue was helpful because as the three little pigs verbalize their plan and rationale, it's easier to understand the thought process that got them to the final solution. When the three little pigs try out a few ideas that do not work, it also demonstrates that it's ok to try out some ideas; they may not work the first time, but if you keep trying you will likely find the solution.

The story was amazing it really helped bring it all together!

For these teacher candidates the stories were as source of motivation: "I wanted to watch to the end," "keep me focused," "really connected." Mathematics was cast as the "message," "the moral of the story", and "the thought processes" of the story characters. 


\section{Visceral Sensations}

Good movies help you experience visceral sensations (such as beauty, fear, disgust, and lust). In the Mathematics for Teachers course, teacher candidates had numerous opportunities (through their hands-on explorations, discussions, interactive animations, and teacher interviews) to experience a sense of mathematics pattern and fit, which give a sense of mathematical beauty.

In movies, visceral sensations are enhanced by the movie soundtrack. Music was also present in the course, through songs from young students and from fellow classmates (see Fig. 7).

That was amazing!! Definitely turns math into a more active and enjoyable subject, especially for students who are intimidated with numbers.

Thank you so much!

I also really enjoyed the songs; I'm a big GreenDay fan, loved the melody choice ;)

I also learned that good math songs will really help when it's time to take a test! I can't get the "making 12" song out of my head now - haha.

In addition, the instructor composed songs that he used to summarize teacher candidate learning, where the songs used as much as possible actual comments made in course discussions. 
Whooaa! This is real cool! all the songs act like a summation to the discussions.

\begin{tabular}{|ll|}
\hline Infinity in my Hand & Cut an apple in half \\
Shade a square One-half & Then the half in half \\
then a quarter & And the half in half in half \\
An eighth and a sixteenth & On and on and on \\
$\begin{array}{l}\text { On and on forever } \\
\text { What's the sum of the parts? }\end{array}$ & You get apple juice or mush \\
My fractions get smaller & Eureka, it still fits in your hand \\
Yet still continue on and on & I am far less intimidated now \\
Can I hold it in my hand? & Infinity does not have to be large \\
& It can be tiny and small \\
Infinity is pretty & Wow, what a great exercise \\
intangible to me & I completely changed \\
Annoyingly elusive & How I look at infinity \\
and abstract & \\
Something monstrous & It's kind of cool \\
or unreachable & A very odd pleasure \\
I feel unsure, frustrated, overwhelmed & To physically do something that \\
But I enjoy & Seems mathematically impossible \\
that it makes me think & To hold infinity \\
Think outside the box & in the palm of my hand \\
& \\
An infinite number of fractions & An infinite number of fractions \\
Can fit in my hand & Can fit in my hand \\
If I display them & If I display them \\
As part of a whole & As part of a whole \\
& \\
& \\
\hline
\end{tabular}

Fig. 7 Lyrics of the song "Infinity in my hand"

\section{What Did You Do in Math Today?}

In this chapter we looked at online mathematics learning for teachers through the four affordances of new media: democratization, multimodality, collaboration and performance. All of these affordances enable us to better connect and communicate with one another in educational settings. It is interesting that mathematics, perhaps more so than other school subjects, has traditionally been a subject that people do not talk about outside of classroom settings. 
However, we have demonstrated through the case of the

Mathematics for Teachers course that this does not have to be the case. Mathematics, even mathematics that traditionally has been seen as abstract or inaccessible, can be talked about in ways that can engage not only adults but also young children.

After doing the activities and watching the videos I learned that it is possible to explain the concept of infinity to everybody.

I guess I was initially thinking that it would be an impossible concept to explain clearly since it doesn't have a beginning or an end but now I see how it is possible.

In fact, many of the teacher candidates in the course did discuss the mathematics of the course with family, friends and colleagues.

My son and I worked on some of the activities together, and math is becoming something fun for me.

After debating with my husband about whether or not you can *actually* hold infinity, I am convinced that indeed you can.

One of my kids walked by and asked if it was the bare naked ladies I was listening to. This has all been ridiculously fun to follow.

The affordances of new media do, in many ways, help us rethink and disrupt our existing views of mathematics (for teachers and for students) and of how it might be taught and learned, by (1) blurring teacher/student distinctions and crossing hierarchical curriculum boundaries; (2) communicating mathematics in multimodal ways; (3) 
seeing mathematics as a collaborative enterprise; and (4) helping us learn how to relate good math stories to classmates and family when asked "What did you do in math today?"

\section{Looking Ahead}

It is important to reiterate that our goal in this case study is not to prove a causal link between the affordances of new media and the design of the Mathematics for Teachers course. Rather, the affordances of new media are used as an analytical lens to better understand how new media affordances may be seen to be manifested or mirrored in our pedagogical choices and teacher candidate interactions in the course. At the same time, the case study is a glimpse of what- might-be in mathematics for teachers courses in a new media setting, especially in helping transform mathematics as a subject that can be discussed with family and friends as one might for a good movie or a favourite book. What needs to be noticed here is that such a transformation of mathematics can be facilitated through the affordances of new media. As such, our case study serves as an artefact for discussion and critique and as a starting point for designing similar or alternative course offerings in online settings. In our work, we continue to develop a capacity for democratization, 
multimodality, collaboration and performance in mathematics

education, for teachers and for students. One example of this is the www.researchideas.ca website, where in collaboration with project schools we are creating multimodal and performative documentaries of how the "content" of our Mathematics-for-Teachers courses has been used in elementary school classrooms.

\section{Authors}

G. Gadanidis \& I.K. Namukasa

Faculty of Education, Western University, London, ON, Canada e-mail:

ggadanid@uwo.ca; inamukas@uwo.ca 


\section{References}

Al-Obaidi, J. (2003). Communication and the culture of democracy: Global media and promotion of democracy in the Middle East. International Journal of Instructional Media, 30(1), 97-110.

Ball, D. L. (2002). Knowing mathematics for teaching: Relations between research and practice. Mathematics and Education Reform Newsletter, 14(3), 1-5.

Ball, D. L., \& Bass, H. (2003). Toward a practice-based theory of mathematical knowledge for teaching. In E. Simmt \& B. Davis (Eds.), Proceedings of the 2002 Annual Meeting of the Canadian Mathematics Education Study Group (pp. 3-14). Edmonton, AB, Canada: CMESG/GCEDM.

Ball, D. L., Bass, H., Sleep, L., \& Thames, M. (2005, May 15-21). A theory of mathematical knowledge for teaching. The Fifteenth ICMI Study: The Professional Education and Develop- ment of Teachers of Mathematics. Rio Claro, Brazil: State University of Sao Paolo. Retrieved October 22, 2005, from http://stwww.weizmann.ac.il/G-math/ICMI/log in.html

Begle, E. G. (1979). Critical variables in mathematics education:

Findings from a survey of the empirical literature. Washington,

DC: Mathematical Association of America and National Council of Teachers of Mathematics.

Boal, A. (1985). Theatre of the oppressed. New York: Theatre Communications Group.

Boorstin, J. (1990). The Hollywood eye: What makes movies work.

New York: Harper Collins Publishers.

Borba, M. C., \& Villarreal, M. E. (2005). Humans-with-media and 
the reorganization of mathe- matical thinking. New York: Springer.

Chester, J. (2007). Digital destiny: New media and the future of democracy. New York: New Press Publishers.

Cuban, L. (1986). Teachers and machines: The classroom use of technology since 1920. New York: Teachers College Press/Columbia University.

Davis, B., \& Simmt, E. (2006). Mathematics-for-teaching: An ongoing investigation of the mathematics that teachers (need to) know. Educational Studies in Mathematics, 61(3), 293-319.

Denzin, N., \& Lincoln, Y. (2005). Introduction: The discipline and practice of qualitative research. In N. K. Denzin \& Y. S. Lincoln (Eds.), The Sage handbook of qualitative research (3rd ed., pp. 1-32). Thousand Oaks, CA: Sage.

Eisenberg, T. A. (1977). Begle revisited: Teacher knowledge and student achievement in algebra. Journal for Research in Mathematics Education, 8, 216-222.

Fennema, E., \& Franke, M. L. (1992). Teachers' knowledge and its impact. In D. A. Grouws (Ed.), Handbook of research on mathematics teaching and learning (pp. 147-164). New York: Macmillan.

Gadanidis, G., \& Borba, M. (2008). Our lives as performance mathematicians. For the Learning of Mathematics, 28(1), 42-49.

Gadanidis, G., Hoogland, C., \& Hughes, J. (2008). Teaching and learning in a Web 2.0 environment: Three case studies. International Journal of Technology for Teaching and Learning, $4(2), 117-133$.

Gadanidis, G., \& Hughes, J. (2011). Performing big math ideas 
across the grades. Teaching Children Mathematics, 17(8), 486496.

Gadanidis, G., \& Namukasa, I. (2005, May 15-21). Math therapy. The Fifteenth ICMI Study: The Professional Education and Development of Teachers of Mathematics. Rio Claro, Brazil: State University of Sao Paolo.

Gadanidis, G., \& Namukasa, I. (2007). Mathematics-for-teachers (and students). Journal of Teaching and Learning, 5(1), 13-22.

General Accounting Office. (1984). New directions for federal programs to aid math and science teaching (GAO/PEMO-85-5). Washington, DC: Author.

Hughes, J. (2008). The performative pull of research with new media. International Journal of Qualitative Methods, 7(3), 16-34.

Kaput, J. (2002). Implications of the shift from isolated, expensive, technology to connected, inexpensive, diverse, and ubiquitous technologies. In F. Hitt (Ed.), Representations and mathematics visualizations (pp.79-109). Mexico: PME-NA, Cinvestav-IPN.

Knobel, M., \& Lankshear, C. (Eds.). (2007). A new literacies sampler. New York: Peter Lang.

Kress, G., \& van Leeuwen, T. (2001). Multimodal discourse: The modes and media of contemporary communication. N.Y.: Oxford University Press.

Lankshear, C., \& Knobel, M. (2006). New literacies: Everyday practices \& classroom learning (2nd ed.). London: Open University Press.

Levy, P. (1993). Tecnologias da Inteligência: O futuro do pensamento na era da informática. [Technologies of 
intelligence: The future of thinking in the informatics era]. Rio de Janeiro, Brazil: Editora 34.

Levy, P. (1998). Becoming virtual: Reality in the digital age. New York: Plenum Press.

Monk, D. H. (1994). Subject area preparation of secondary mathematics and science teachers and student achievement. Economics of Education Review, 13(2), 125-145.

NCTM. (2000). Principles and standards for school mathematics. Reston, VA: NCTM.

Norman, D. A. (2004). Emotional design: Why we love (or hate) everyday things. New York: Basic Books.

Ontario Ministry of Education. (2005). The Ontario curriculum grades 1-8: Mathematics (Revised). Toronto, ON, Canada: Ontario Ministry of Education.

Patton, M. Q. (2002). Qualitative research and evaluation methods (3rd ed.). Thousand Oaks, CA: Sage.

Schrage, M. (2001). The relationship revolution. http://web.archive.org/web/20030602025739/ http://www.ml.com/woml/forum/relation.htm. Accessed 12 July 2008.

Stake, R. (2000a). Case studies. In N. Denzin \& Y. Lincoln (Eds.), Handbook of qualitative research (2nd ed., pp. 435-454). Thousand Oaks, CA: Sage Publications.

Stake, R. E. (2000b). The case study method in social inquiry. In R. Gomm, M. Hammersley, \&

P. Foster (Eds.), Case study method: Key issues, key texts. London: Sage Publications.

Tall, D., \& Tirosh, D. (2001). Infinity the never ending struggle. 
Educational Studies in Mathematics, 48, 129-136.

Wikipedia. (2011). Zeno of Elea. http://en.wikipedia.org/wiki/Zeno of Elea. Accessed 6 July 2011.

Yin, R. K. (2006). Case study methods. In J. L. Green, G. Camilli, \& P. B. Moore (Eds.), Handbook of complementary methods in educational research (pp. 279-298). Mahwah, NJ: Lawrence Erlbaum Associates. 